05

\title{
Износ и коэффициент трения супермодифицированного заэвтектического сплава алюминия с кремнием
}

\author{
() В.Н. Осипов, ${ }^{1}$ Ю.А. Фадин, ${ }^{2}$ С.П. Никаноров ${ }^{1}$ \\ ${ }^{1}$ Физико-технический институт им. А.Ф. Иоффре, \\ 194021 Санкт-Петербург, Россия \\ ${ }^{2}$ Институт проблем машиноведения РАН, \\ 199178 Санкт-Петербург, Россия \\ e-mail: s.nikanorov@mail.ioffe.ru
}

Поступило в Редакцию 3 февраля 2020 г.

В окончательной редакции 26 мая 2020 г.

Принято к публикации 26 мая 2020 г.

\begin{abstract}
Изучены коэффициент трения и износ заэвтектического по составу сплава алюминия с $15 \mathrm{wt} . \%$ кремния с супермодифицированной эвтектической структурой без первичных кристаллов кремния, полученного направленной кристаллизацией при скорости затвердевания $1 \mathrm{~mm} / \mathrm{s}$. Показано, что этот сплав с высокой прочностью и пластичностью имеет более низкий коэффициент трения и более высокое сопротивление износу, чем сплав с 20 wt.\% кремния. После модификации стронцием его трибологические свойства превосходят свойства заэвтектического коммерческого сплава.
\end{abstract}

Ключевые слова: микроструктура и механические свойства, трение и износ.

DOI: $10.21883 / J T F .2020 .12 .50124 .70-20$

\section{Введение}

В различных отраслях техники широко используются литейные сплавы алюминия с кремнием благодаря высокому отношению прочности к весу, низкому коэффициенту теплового расширения, высоким литейным качествам и сопротивлению коррозии. Заэвтектические $\mathrm{Al}-\mathrm{Si}-$ сплавы с содержанием кремния более $13 \mathrm{wt} . \%$ имеют большее сопротивление износу и более низкий коэффициент трения, чем доэвтектические сплавы. Они наиболее интересны при производстве поршней, цилиндров и блоков двигателей внутреннего сгорания для современного автомобиля и спиральных компрессоров.

В [1] показано, что прочность направленно кристаллизованных заэвтектических $\mathrm{Al}-\mathrm{Si}$-сплавов растет при увеличении содержания кремния до эвтектического, около $12.5 \mathrm{wt. \%}$, и падает в заэвтектической области. Это связано с ростом крупных первичных кристаллов кремния, границы которых при деформации становятся концентраторами напряжений. В то же время первичные кристаллы кремния, имеющего высокие модули упругости, обеспечивают заэвтектическому сплаву меньший коэффициент трения и большее сопротивление износу. Эти свойства зависят от размера и морфологии как первичных кристаллов кремния, так и эвтектического кремния. Поэтому в настоящее время ведутся интенсивные исследования возможности одновременного увеличения прочности, твердости и улучшения трибологических свойств заэвтектических сплавов [2]. Авторы работы [3] показали эффективность направленной кристаллизации заэвтектического сплава в эвтектической точке, смещенной к повышенному содержанию кремния за счет такого увеличения скорости затвердевания, ко- торое обеспечит образование эвтектической структуры без первичных кристаллов. В этой работе был получен сплав $\mathrm{Al}-15 \mathrm{wt} . \% \mathrm{Si}$ при скорости затвердевания $v$, равной $1 \mathrm{~mm} / \mathrm{s}$, с тонкодисперсной эвтектической структурой без первичных кристаллов кремния с повышенной прочностью и пластичностью. Модификация этого сплава 0.01 wt.\% Sr усилила рафинирование сплава. Его супермодифицированная эвтектическая микроструктура стала оптически неразличимой по фазам и соответствует высшему шестому рейтингу Американского литейного общества [4]. Этот сплав имеет повышенную прочность, рекордную величину остаточного удлинения при разрушении, а его коэффициент качества выше, чем у всех силуминов. Однако трибологические свойства этого сплава не изучены.

В настоящей работе исследовалось трение и износ немодифицированого и модифицированного стронцием сплава заэвтектического состава $\mathrm{Al}-15 \mathrm{wt} . \% \mathrm{Si}$ с эвтектической структурой без первичных кристаллов, полученной в смещенной эвтектической точке при $v=1 \mathrm{~mm} / \mathrm{s}$, а также заэвтектического сплава $\mathrm{Al}-20 \mathrm{wt} . \% \mathrm{Si}$ и технического алюминия.

\section{1. Получение сплавов и определение их характеристик}

Все сплавы были получены из $99.9 \% \mathrm{Al}$ и $99.8 \% \mathrm{Si}$. Расплав гомогенизировался при $800^{\circ} \mathrm{C}$ в течение нескольких часов при периодическом перемешивании. Затем был приготовлен промежуточный сплав из $\mathrm{Al}-15$ wt.\% Si и 9 wt.\% $\mathrm{Sr}$ чистотой $99.9 \%$. Стронций необходимого веса до погружения в расплав завертывал- 

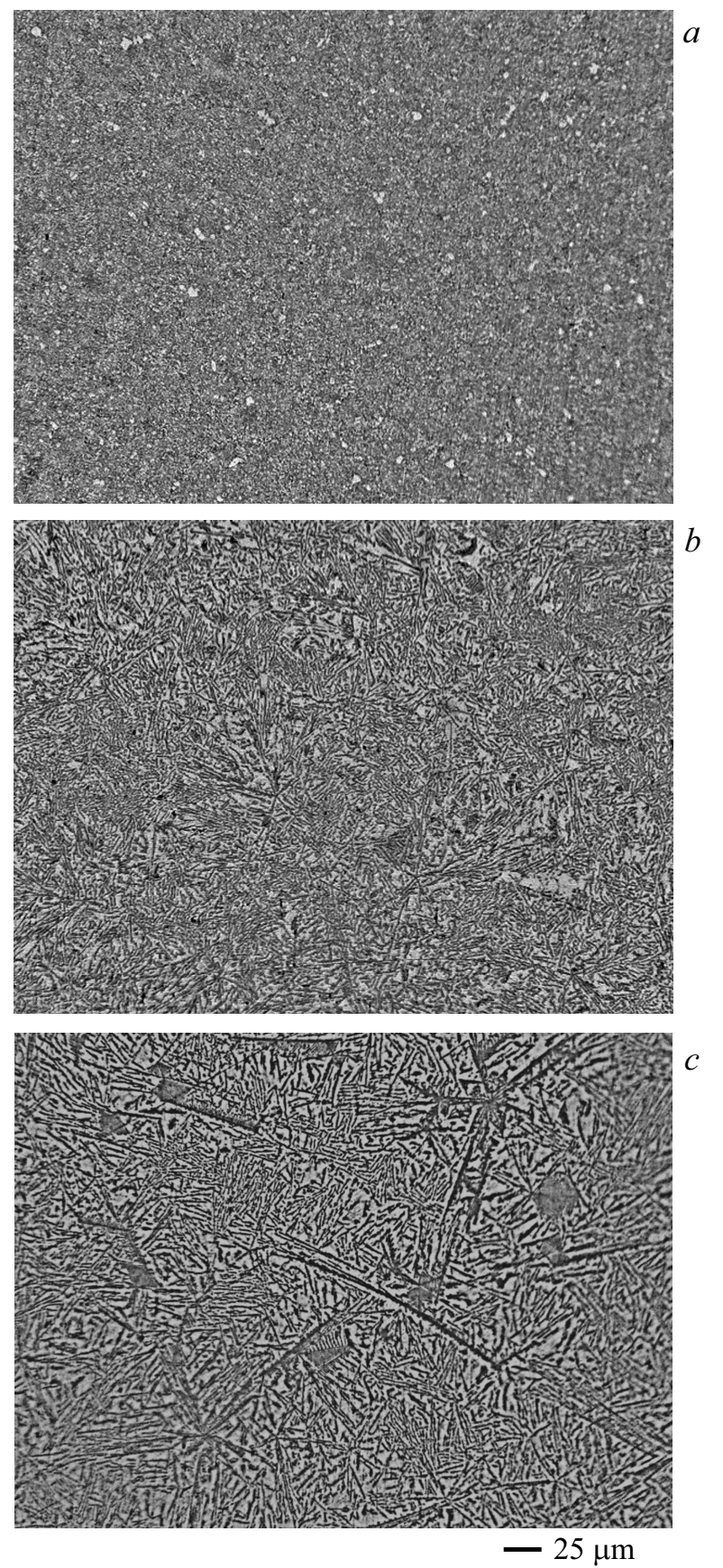

Рис. 1. Микроструктура алюминиевых сплавов, полученных направленной кристаллизацией, скорость затвердевания $1 \mathrm{~mm} / \mathrm{s}$, поперечное сечение: $a-\mathrm{Al}-15 \mathrm{Si}-0.01 \mathrm{wt} \% \mathrm{Sr}, b-$ $\mathrm{Al}-15$ wt.\% Si, $c-\mathrm{Al}-20$ wt.\% Si. Увеличение для всех шлифов показано на $c$.

ся в алюминиевую фольгу 99.9\% чистоты для предотвращения окисления. Промежуточный сплав гомогенизировался в течение $3 \mathrm{~h}$ при $800^{\circ} \mathrm{C}$ с перемешиванием каждый час. Этот сплав использовался для получения модифицированного сплава $\mathrm{Al}-15$ wt.\% $\mathrm{Si}-0.01$ wt.\% Sr, расплав которого до затвердевания выдерживался также в течение $3 \mathrm{~h}$ при $800^{\circ} \mathrm{C}$ с перемешиванием каждый час [3]. Стержни длиной около $1 \mathrm{~m}$ и поперечным сечением $15 \times 3 \mathrm{~mm}$ вытягивались из расплава $660^{\circ} \mathrm{C}$ через формообразователь с воздушным охлаждением способом Степанова. Скорость затвердевания была $1 \mathrm{~mm} / \mathrm{s}$, температурный градиент около $12 \mathrm{~K} / \mathrm{min}$ [5]. Микроструктура шлифов этих сплавов показана на рис. 1.

Трение и износ материала изучались при контакте торца неподвижного стержня исследуемого материала и вращающегося диска из стали марки 45. Нагрузка на контакт была $5.5 \mathrm{~N}$ (давление в области $0.3-0.6 \mathrm{MPa}$ для образцов с разным сечением) при линейной скорости вращения 0.5 и $5.4 \mathrm{~m} / \mathrm{s}$. Коэффициент трения скольжения $f$ определялся по моменту силы трения: $f=M /(r P)$, где $M$ - момент силы трения скольжения, $r$ - расстояние от оси вращения до места приложения нагрузки, $P$ - нормальная нагрузка. На основании данных о весовом износе и плотности рассчитывалась интенсивность изнашивания сплава $W=\Delta V /(S L)$. Здесь $\Delta V$ - износ объема, $S$ - площадь сечения образца, $L$ - длина пути трения. Этот параметр характеризует уменьшение объема на единицу площади на единице пути трения и выражается в безразмерных единицах.

\section{2. Результаты и их обсуждение}

Результаты измерений для двух скоростей скольжения приведены в табл. 1 и 2. В этих таблицах приведены значения коэффициента трения, измеренные при такой длительности испытания, которая соответствует установившемуся характеру изменения $f$ со временем. Это видно из рис. 2 и 3 , где приведены зависимости коэффициента трения от времени при скорости скольжения 5.4 и $0.5 \mathrm{~m} / \mathrm{s}$. Зависимости коэффициента трения от времени имеют минимум и область роста до постоянной установившейся величины. Исключение наблюдается в случае сплава $\mathrm{Al}-20 \mathrm{wt} . \% \mathrm{Si}$ при скорости скольжения $0.5 \mathrm{~m} / \mathrm{s}$. Зависимость $f(t)$ имеет перегиб в области $20 \mathrm{~s}$ и достигает постоянной величины 0.18, а затем уменьшается до 0.12 (рис. 3,d). Увеличение $f$ со временем или расстоянием скольжения объясняется увеличением шероховатости поверхности контакта в процессе трения, которое ранее наблюдалось на алюминии в работе [6]. Второй причиной медленного роста коэффициента трения во всем исследованном интервале температур могло быть повышение температуры вблизи контакта. Так, измерения в работе [7] показали, что температура сплава $\mathrm{Al}-25 \mathrm{wt} . \% \mathrm{Si}$ повышается вблизи контакта со сталью при близких условиях трения (давление $10 \mathrm{~N}$, скорость скольжения $1 \mathrm{~m} / \mathrm{s}$ ) до $40^{\circ} \mathrm{C}$ при расстоянии скольжения до $2000 \mathrm{~m}$. Аномальное поведение $f$ сплава $\mathrm{Al}-20$ wt.\% Si при скорости скольжения $0.5 \mathrm{~m} / \mathrm{s}$ может быть связано с неоднородностью микроструктуры, образованной первичными кристаллами кремния.

Наблюдаемая интенсивность износа при нагрузке $5.5 \mathrm{~N}$ и обеих выбранных скоростях скольжения соответствует области умеренного износа сплавов $\mathrm{Al}-\mathrm{Si}$, 
Таблица 1. Состав сплава, характеристики условий и результаты трибологических испытаний при нагрузке $5.5 \mathrm{~N}$ и скорости $5.4 \mathrm{~m} / \mathrm{s}$

\begin{tabular}{c|c|c|c|c|c|c|c}
\hline Состав $^{*}$ & $\begin{array}{c}\text { Сечение } \\
\text { образца, } \\
\mathrm{mm}^{2}\end{array}$ & $\begin{array}{c}\text { Путь } \\
\text { трения, } \\
\mathrm{m}\end{array}$ & $\begin{array}{c}\text { Износ } \\
\text { по весу, } \\
\Delta W, \mathrm{mg}\end{array}$ & $\begin{array}{c}\text { Относительная скорость } \\
\text { износа по весу, } \\
W_{R}, \mathrm{mg} / \mathrm{m}, 10^{-4}\end{array}$ & $\begin{array}{c}\text { Изношенный } \\
\text { объем, } \\
\Delta V, \mathrm{~mm}^{3}\end{array}$ & $\begin{array}{c}\text { Интенсивность } \\
\text { изнашивания, } W, \\
\text { в единицах } 10^{-8}\end{array}$ & $\begin{array}{c}\text { Коэффициент } \\
\text { трения } \\
f\end{array}$ \\
\hline $\mathrm{Al}$ & 20 & 1574 & 2.6 & 16.5 & 0.96 & 3.0 & 0.31 \\
\hline $\mathrm{Al}-15 \mathrm{Si}-0.01 \mathrm{Sr}$ & 15.3 & 1270 & 1.2 & 9.46 & 0.43 & 2.2 & 0.28 \\
\hline $\mathrm{Al}-15 \mathrm{Si}$ & 13.68 & 1765 & 2.4 & 13.6 & 0.86 & 3.6 & 0.28 \\
\hline $\mathrm{A} 1-20 \mathrm{Si}$ & 9.72 & 1626 & 3.6 & 22.1 & 1.29 & 8.2 & 0.29
\end{tabular}

Примечание. * Состав дан в wt.\%.

Таблица 2. Состав сплава, характеристики условий и результаты трибологических испытаний при нагрузке 5.5 N и скорости $0.5 \mathrm{~m} / \mathrm{s}$

\begin{tabular}{|c|c|c|c|c|c|c|c|}
\hline Состав ${ }^{*}$ & $\begin{array}{l}\text { Сечение } \\
\text { образца, } \\
\mathrm{mm}^{2}\end{array}$ & $\begin{array}{c}\text { Путь } \\
\text { трения, } \\
\text { m }\end{array}$ & $\begin{array}{c}\text { Износ } \\
\text { по весу, } \\
\Delta W, \mathrm{mg}\end{array}$ & $\begin{array}{c}\text { Относительная скорость } \\
\text { износа по весу, } \\
W_{R}, \mathrm{mg} / \mathrm{m}, 10^{-4}\end{array}$ & $\begin{array}{c}\text { Изношенный } \\
\text { объем, } \\
\Delta V, \mathrm{~mm}^{3}\end{array}$ & $\begin{array}{c}\text { Интенсивность } \\
\text { изнашивания, } W, \\
\text { в единицах } 10^{-8}\end{array}$ & $\begin{array}{c}\text { Коэффициент } \\
\text { трения } \\
f\end{array}$ \\
\hline $\mathrm{Al}$ & 17.6 & 331 & 1.8 & 54 & 0.67 & 11.5 & 0.28 \\
\hline $\mathrm{Al}-15 \mathrm{Si}-0.01 \mathrm{Sr}$ & 14.3 & 391 & 1.6 & 41 & 0.57 & 10.2 & 0.26 \\
\hline $\mathrm{Al}-15 \mathrm{Si}$ & 13.0 & 326 & 1.2 & 37 & 0.43 & 10.1 & 0.28 \\
\hline $\mathrm{Al}-20 \mathrm{Si}$ & 4.8 & 407 & 1.7 & 42 & 0.60 & 30.7 & 0.18 \\
\hline
\end{tabular}

Примечание. * Состав дан в wt.\%.

что следует из результатов многих наблюдений, рассмотренных в [8]. Согласно измерениям [9], на сплаве $\mathrm{Al}-25$ wt.\% Si при скорости скольжения $1 \mathrm{~m} / \mathrm{s}$ умеренный износ имеет две области: легкий износ при нагрузке до $60 \mathrm{~N}$ и повышенный износ при нагрузке до $150 \mathrm{~N}$. Выше $150 \mathrm{~N}$ наблюдается жесткий износ, скорость износа возрастает на порядок. Этот переход зависит и от скорости скольжения. Умеренный износ объясняют износом окисленного или окисляющегося при трении поверхностного слоя сплавов [9].

Согласно табл. 1 и 2, увеличение скорости от 0.5 до $5.4 \mathrm{~m} / \mathrm{s}$ при нагрузке $5.5 \mathrm{~N}$ приводит к уменьшению интенсивности изнашивания $W$ сплава одного состава на $64-78 \%$.

Можно было предположить, что увеличение содержания кремния в исследуемых заэвтектических сплавах приведет к увеличению сопротивления износу, потому что кремний имеет высокий модуль упругости и является несущим нагрузку элементом в сплаве. Однако из табл. 1 и 2 видно, что увеличение содержания кремния вызывает не увеличение, а уменьшение сопротивления износу. Увеличение содержания кремния в сплаве $\mathrm{Al}-20 \mathrm{wt} . \% \mathrm{Si}$ по сравнению с $\mathrm{Al}-15$ wt.\% Si соответствует увеличению интенсивности изнашивания от $3.6 \cdot 10^{-8}$ до $8.2 \cdot 10^{-8}$, т.е. на $56 \%$, при скорости скольжения $5.4 \mathrm{~m} / \mathrm{s}$ или от $10.1 \cdot 10^{-8}$ до $30.7 \cdot 10^{-8}$, т.е. на $67 \%$, при скорости скольже- ния $0.5 \mathrm{~m} / \mathrm{s}$ (табл. 1 и 2). Это изменения объясняются тем, что сплав $\mathrm{Al}-15 \mathrm{wt} . \% \mathrm{Si}$ был кристаллизован в смещенной эвтектической точке при независимом парном росте компонент структуры. Он имеет тонкую чешуйчато-волокнистую эвтектическую микроструктуpy. Сплав $\mathrm{Al}-20 \mathrm{wt} . \% \mathrm{Si}$ состоит из эвтектики и первичных кристаллов кремния дендритной, звездной и перистой структур (рис. 1). При модификации сплава $\mathrm{Al}-15$ wt.\% Si стронцием произошло дальнейшее утончение микроструктуры эвтектики до супермодифицированной, неразрешимой оптической микроскопией. Интенсивность изнашивания понизилась при скорости скольжения $5.4 \mathrm{~m} / \mathrm{s}$ на $39 \%$, а при скорости $0.5 \mathrm{~m} / \mathrm{s}$ осталась неизменной. Можно считать, что интенсивность износа определяется главным образом морфологией и размером эвтектического кремния и первичных кристаллов кремния.

Таким образом, можно считать, что интенсивность износа заэвтектического сплава алюминия с кремнием при заданном содержании кремния, полученного при такой повышенной скорости, которая обеспечивает образование однофазной эвтектической микроструктуры в смещенной эвтектической точке, минимальна по сравнению с износом других близких составов, полученных при этой скорости затвердевания. Представляется важным сравнить результаты измерения трибологических характеристик $\mathrm{Al}-15$ wt.\% Si сплава заэвтектического 

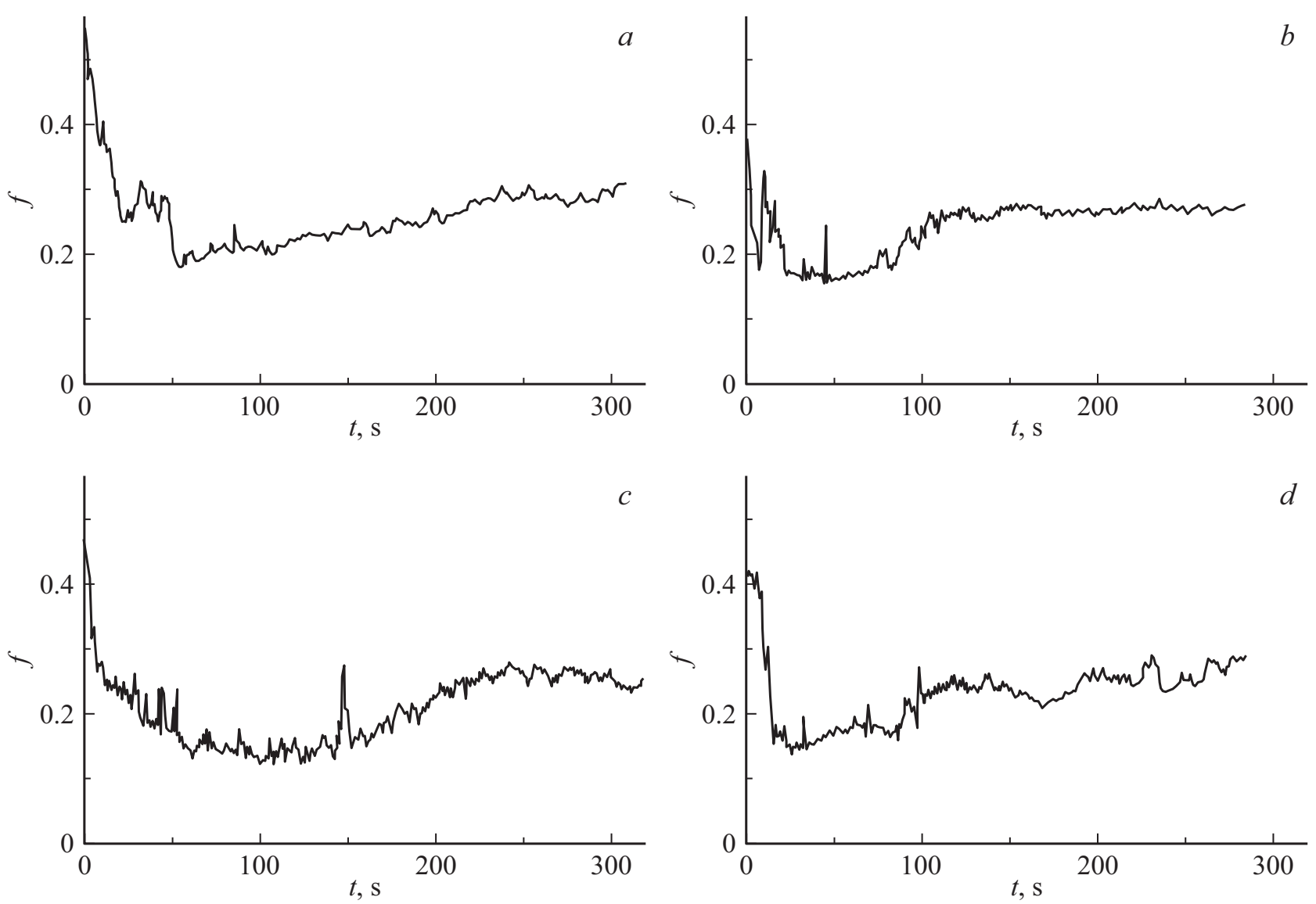

Рис. 2. Зависимость коэффициента трения от времени скольжения $t$ при нагрузке $5.5 \mathrm{~N}$ и скорости скольжения $5.4 \mathrm{~m} / \mathrm{s}: a-\mathrm{Al}$, $b-\mathrm{Al}-15 \mathrm{wt} . \% \mathrm{Si}, c-\mathrm{Al}-15 \mathrm{wt} . \% \mathrm{Si}-0.01 \mathrm{wt} . \% \mathrm{Sr}, d-\mathrm{Al}-20 \mathrm{wt} . \% \mathrm{Si}$.

состава (более 12.5 wt.\% Si), но с эвтектической структурой, с характеристиками коммерческого заэвтектического сплава, применяемого при изготовлении частей двигателей внутреннего сгорания. Следует отметить, что в литературе нет измерений, выполненных на коммерческих заэвтектических сплавах с составом, исследованным в настоящей работе, и при одинаковых условиях испытаний. Поэтому здесь проводится сопоставление со сплавом $390 \mathrm{Al}$ с близким содержанием кремния по тем трибологическим характеристикам, которые исследовались в работе [9].

Скорость износа по весу $W_{R}$ оценивалась по потере веса образца $\Delta W$ на пути трения $L$ :

$$
W_{R}=\Delta W / L \text {. }
$$

Скорость износа по объему определялась следующим образом:

$$
W_{V}=\Delta V / t \text {. }
$$

Удельная скорость износа $W_{s}$ определялась потерей объема на единицу длины пути и приложенной нормально нагрузки:

$$
W_{s}=\Delta V /(L P) .
$$

Состав сравниваемых сплавов, механические характеристики, трибологические характеристики и условия испытаний приведены в табл. 3. Коммерческий литой сплав $390 \mathrm{Al}$ в отличие от сплава $\mathrm{Al}-15$ wt.\% Si coдержит примеси $\mathrm{Mg}, \mathrm{Cu}, \mathrm{Fe}, \mathrm{Ni}$, более $1 \mathrm{wt} . \%$ каждой. Известно, что эти примеси упрочняют и одновременно охрупчивают сплав алюминия с кремнием. Это одна из причин того, что его прочность выше на 10\%, а остаточная деформация меньше на $60 \%$, чем у сплава, исследуемого в нашей работе. Однако после модификации исследуемого сплава стронцием прочность сплава $\mathrm{Al}-15$ wt.\% $\mathrm{Si}-0.01$ wt.\% $\mathrm{Sr}$ становится выше на 8\%, а остаточная деформация - больше на $500 \%$ по сравнению с коммерческим сплавом. Основная причина в том, что сплав $390 \mathrm{Al}$ состоит из эвтектики, образованной $\alpha$-Al и чешуйчатым эвтектическим кремнием, объемных первичных кристаллов кремния и частиц $\mathrm{Mg} 2 \mathrm{Si}$, а модифицированный стронцием сплав алюминия с кремнием имеет супертонкую дисперсную эвтектическую структуру без первичных кристаллов. В этом причина того, что $W_{s}, W_{V}, W_{R}$ и у сплава заэвтектического состава с супермодифицированной структурой значительно меньше, чем для коммерческого сплава, как видно из табл. 3. Следует отметить, что трибологические характеристики сплава $390 \mathrm{Al}$ измерялись в [9] при нагрузке $10 \mathrm{~N}$, а алюминий кремниевых сплавов в настоящей работе 

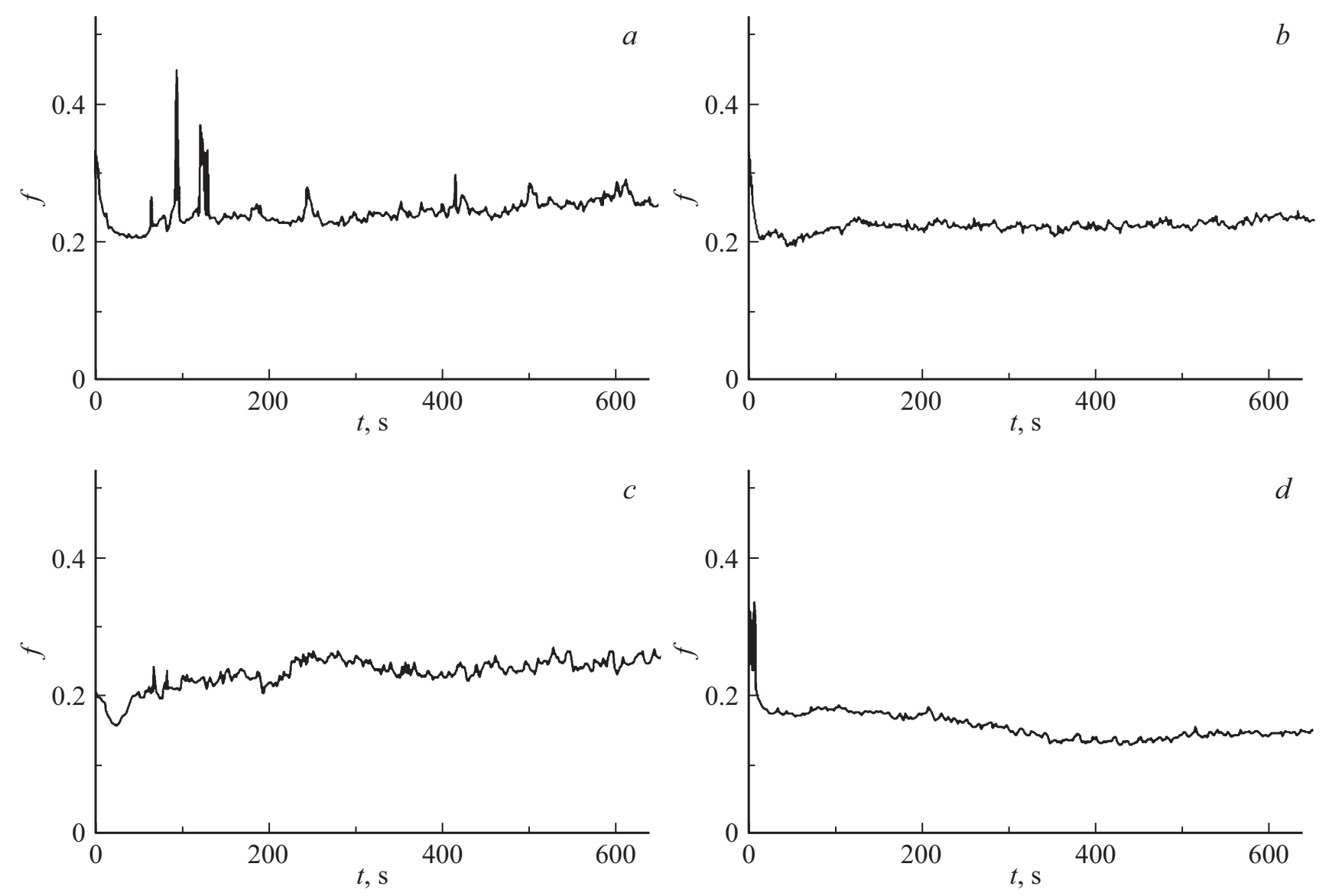

Рис. 3. Коэффициент трения $f$ в зависимости от времени скольжения $t$ при нагрузке $5.5 \mathrm{~N}$ и скорости скольжения $0.5 \mathrm{~m} / \mathrm{s}: a-\mathrm{Al}$, $b-\mathrm{Al}-15$ wt.\% Si-0.01 wt.\% Sr, $c-\mathrm{Al}-15$ wt.\% Si, $d-\mathrm{Al}-20$ wt.\% Si.

Таблица 3. Состав сплава, временная прочность при растяжении $\sigma$, удлинение при разрушении $\varepsilon$ и трибологические характеристики сплавов при нагрузке $P$ и скорости скольжения $v$

\begin{tabular}{|c|c|c|c|c|c|c|c|c|}
\hline Сплав* & $\sigma, \mathrm{MPa}$ & $\varepsilon, \%$ & $P, \mathrm{~N}$ & $v, \mathrm{~ms}^{-1}$ & $\begin{array}{c}\text { Удельная скорость } \\
\text { износа } W_{s}, \\
10^{-13} \mathrm{~m}^{3} /(\mathrm{N} \cdot \mathrm{m})\end{array}$ & $\begin{array}{c}\text { Скорость Износа } \\
\text { объема } W_{V}, \\
10^{-12} \mathrm{~m}^{3} / \mathrm{s}\end{array}$ & $\begin{array}{c}\text { Скорость } \\
\text { износа } W_{R}, \\
10^{-6} \mathrm{~N} / \mathrm{m}\end{array}$ & $\begin{array}{c}\text { Источник данных; } \\
\text { коэффициент } \\
\text { трения } f\end{array}$ \\
\hline $390 \mathrm{Al}^{* *}$ & 250 & 5.4 & 10 & 5.3 & 2.852 & 8.558 & 0.08 & $\begin{array}{c}{[9] ; f=3.0,} \\
\text { шероховатость } 0.2 \mu \mathrm{m}\end{array}$ \\
\hline $\mathrm{Al}-15 \mathrm{Si}-0.01 \mathrm{Sr}$ & 270 & 32.5 & 5.5 & 5.4 & 0.62 & 1.8 & 0.0094 & \multirow{3}{*}{$\begin{array}{c}\text { Данная работа } \\
f=0.28-0.29\end{array}$} \\
\hline $\mathrm{Al}-15 \mathrm{Si}$ & 225 & 13.5 & 5.5 & 5.4 & 0.89 & 2.6 & 0.0014 & \\
\hline $\mathrm{Al}-20 \mathrm{Si}$ & 125 & 2.5 & 5.5 & 5.4 & 1.44 & 4.3 & 0.022 & \\
\hline
\end{tabular}

Примечание. * Состав сплавов в wt.\%; ** химический состав $390 \mathrm{Al}$ : $\mathrm{Al}-16.69 \mathrm{Si}-1.176 \mathrm{Mg}-1.304 \mathrm{Cu}-1.130 \mathrm{Fe}-1.224 \mathrm{Ni}-0.024 \mathrm{Mn}-0.012 \mathrm{Sn}$ $-0.26 \mathrm{~Pb}-0.12 \mathrm{Zn}$; ${ }^{* * *}$ значения $\sigma$ и $\varepsilon$ из работ [1 и 3 ].

при 5.5 N. Однако по данным [9] увеличение нагрузки в 2 раза, от 10 до $20 \mathrm{~N}$, приводит к снижению $W_{s}$ на $26 \%$ и увеличению $W_{V}$ и $W_{R}$ соответственно на 48 и 43\%. Из табл. 3 видно, что изменения характеристик за счет изменения материала значительно превышают влияние различия в нагрузках: $W_{s}, W_{V}, W_{R}$ сплава $\mathrm{Al}-15$ wt.\% $\mathrm{Si}-0.01$ wt.\% $\mathrm{Sr}$ меньше чем для $390 \mathrm{Al}$ coответственно на 72, 79 и $88 \%$.

\section{Выводы}

- Сплав заэвтектического состава 15 wt.\% Si, полученный в смещенной эвтектической точке за счет повышенной скорости затвердевания $(1 \mathrm{~mm} / \mathrm{s})$ имеет более низкий коэффициент трения и более низкие параметры износа $W_{s}, W_{V}, W_{R}$, чем сплав с $20 \mathrm{wt} . \% \mathrm{Si}$. Низкие трибологические характеристики этого сплава объясня- 
ются его тонкой чешуйчато-волокнистой эвтектической микроструктурой при отсутствии или малом содержании первичных кристаллов кремния.

- Модификация этого сплава $0.01 \mathrm{wt} . \% \mathrm{Sr}$ усиливает этот эффект. Износ веса на единицу длины пути скольжения, скорости износа объема во времени, удельный износ объема на единице длины расстояния скольжения и на единицу приложенной нагрузки ниже, чем для коммерческого заэвтектического сплава $390 \mathrm{Al}$, применяемого для изготовления гильз и поршней двигателей внутреннего сгорания для автомобилей, при близких условиях испытаний.

\section{Конфликт интересов}

Авторы заявляют, что у них нет конфликта интересов.

\section{Список литературы}

[1] С.П. Никаноров, Л.И. Деркаченко, Б.К. Кардашев, Б.Н. Корчунов, В.Н. Осипов, В.В. Шпейзман. ФТТ, 55 (6), 1119 (2013). [S.P. Nikanorov, L.I. Derkachenko, B.K. Kardashev, B.N. Korchunov, V.N. Osipov, V.V. Shpeizman. Physics Solid State, 55 (6), 1207 (2013).]

[2] V.V.K. Narayan Prabhu. Trans. Indian Inst. Met., 67 (1), 1 (2014).

[3] А.И. Аверкин, Б.Н. Корчунов, С.П. Никаноров, В.Н. Осипов. Письма в ЖТФ, 42 (4), 67 (2016). [A.I. Averkin, B.N. Korchunov, S.P. Nikanorov, V.N. Osipov. Techn. Phys. Lett., 42 (2), 201 (2016).]

[4] G.K. Sigworth. Modern Casting, 77, 23 (1987).

[5] П.И. Антонов, Л.М. Затуловский, А.С. Костыгов, Д.И. Левинзон, С.П. Никаноров, В.В. Пеллер, В.А. Татарченко, В.С. Юферев. Получение профилированных монокристаллов и изделий методом Степанова (Наука, Ленинград, 1981), С. 200.

[6] Dewan Muhammad Nuruzzaman, Mohammad Asaduzzaman Chowdhury. Intern. Trans. Eng., Manag., Aplied Sci., Technol., 4 (1), 29 (2013).

[7] M. Elmadagli, T. Perry, A.T. Alpas. Wear., 262 (1-2), 79 (2007). DOI: 10.1016/j.wear.2006.03.043

[8] V. Vijeesh, K. Narayan. Prabhu. Trans. Indian Inst. Met., 67 (1), 1 (2014).

[9] A. Riyadh, Al-Samarai, Haftirman, Khairel Rafezi Ahmad, Y. Al-Douri, Intern. J. Mechan. Product. Eng. Res. Development (IJMPERD), 3 (1), 111 (2013). ISSN2249-6890 